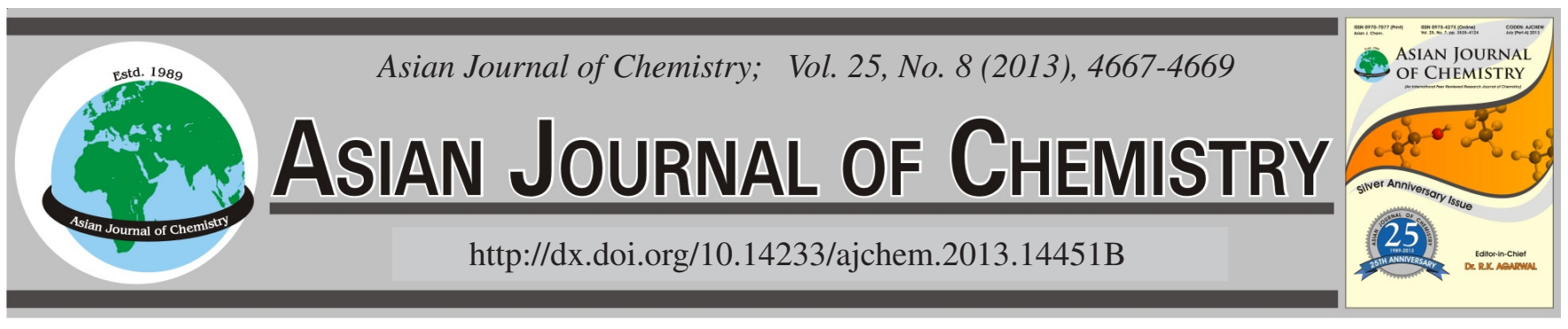

\title{
New Compound from the Heat Processed Roots of Panax ginseng
}

\author{
Ill-Min Chung ${ }^{1}$, Mohd Ali², Youn-Pyo Hong ${ }^{3}$ and Ateeque Ahmad ${ }^{1, *}$
}

${ }^{1}$ Department of Applied Life Science, Konkuk University, Seoul 143-701, South Korea

${ }^{2}$ Faculty of Pharmacy, Hamdard University, New Delhi-110 062, India

${ }^{3}$ Herbal Crop Utilization Research Team, NIHHIS, RDA, Eumseong 369-873, South Korea

*Corresponding author: Fax: +82 2446 7856; Tel: +82 2450 3730; E-mail: ateeque97@ gmail.com

(Received: 17 August 2012;

Accepted: 18 February 2013)

AJC-13039 One new compound dammar-9(11),24-dien-3 $\beta$-ol-3 $\alpha$-L-arabinosyl-7 $\alpha$-octanoate along with the known compound $\beta$-sitosterol- $\beta$-D-
glucoside were isolated and identified from the heat processed roots of Panax ginseng. The chemical structure of new compound was
elucidated by 1D and 2D NMR spectroscopic techniques (COSY, HSQC, HMBC) aided by FAB-MS and IR spectra.

Key Words: Panax ginseng, Araliaceae, Heat processed roots, New constituent, Dammar-9(11), 24-Dien-3 $\beta$-ol-3 $\alpha$-L-arabinosyl$7 \alpha$-octanoate

\section{INTRODUCTION}

Ginseng (Panax ginseng C.A. Meyer, Araliaceae) is one of the most important oriental medicinal plants in Japan, Korea and China ${ }^{1,2}$. Of the two kinds of ginseng, white ginseng is air dried and red ginseng is produced by steaming raw ginseng at $98-100{ }^{\circ} \mathrm{C}$ for $2-4 \mathrm{~h}$. It has been reported that red ginseng is more effective in pharmacological activities than white ginseng ${ }^{2-6}$. The differences in biological activities and chemical constituents of red and white ginsengs have been reported. Ginseng saponins ${ }^{7}$ are known as ginsenosides and have an important role in pharmacological activities ${ }^{8}$. Anticarcinogenic and antidiabetic effects of Panax ginseng have been reported ${ }^{9,10}$. Acetylenic compounds from the ginseng roots $P$. ginseng also reported $^{11,12}$. The most well known chemical constituent of ginseng is ginsenosides, which is a dammarane glycosides. Dammarane glycosides were reported from heat processed ginseng (Korean red Ginseng) ${ }^{13-16}$. Other useful references were available for Ginseng and Panax species ${ }^{17-22}$.

In continuation of our previous work ${ }^{23}$ on $P$. ginseng roots one more new compound (1) was isolated as natural product. This paper deals with the isolation and structure elucidation of one new compound, dammar-9(11), 24-dien-3 $\beta$-ol-3 $\alpha$-Larabinosyl- $7 \alpha$-octanoate (Fig. 1 ) on the basis of ${ }^{1} \mathrm{H}$ and ${ }^{13} \mathrm{C}$ NMR, spectroscopic studies, including 2D NMR, COSY, HMBC, HSQC, FAB-MS, IR spectroscopy and chemical reactions from the heat processed roots of $P$. ginseng. Due to significance of ginseng roots of this plant as a medicinal, the work in this area has already been done. The aim of the present investigation is to report new finding in the form of natural product from Korean red ginseng of $P$. ginseng.

The methanol extract of heat processed roots of $P$. ginseng was suspended in water and extracted with hexane, ethyl acetate and then $n$-butanol. The $n$-butanol extract was separated by a combination of column chromatography over silica gel and Lichroprep RP-18 (ODS Si gel) to yield one new compound along with known compound.

\section{EXPERIMENTAL}

Optical rotation was measured with an instrument on an AA-10 model polarimeter (Instruments Ltd., Seoul, South Korea). IR spectra were recorded on a Infinity Gold FT-IR (Thermo Mattson, USA) spectrophotometer, which was available at Korea Institute of Science and Technology, Seoul, South Korea. Both ${ }^{1} \mathrm{H}$ and ${ }^{13} \mathrm{C}$ NMR spectra were obtained on a Bruker Avance 600 high resolution spectrometer operating at 600 and $150 \mathrm{MHz}$, respectively. All NMR spectra were recorded at Seoul National University (Instrument, Bruker, Germany). NMR spectra were obtained in deuterated solvents using tetramethylsilane (TMS) as an internal standard, with chemical shifts expressed in ppm $(\delta)$ and coupling constants $(J)$ in Hz. FAB/MS data were recorded on a JMS-700 (Jeol, Japan) spectrometer instrument which was available at Seoul National University, Seoul, South Korea. All chemicals used were of analytical grade. Hexane, ethyl acetate, chloroform, methanol, ethanol, water, sulphuric acid and vanillin were purchased from Daejung Chemicals and Metals Co. Ltd., Shiheung (Gyeonggi-do) Korea. Pre-coated TLC plates (layer 
thickness $0.25 \mathrm{~mm}$ ), silica gel for column chromatography (70-230 mesh ASTM) and LiChroprep RP-18 (40-63 $\mu \mathrm{m})$ were from Merck, Darmstadt, Germany. Previously isolated authentic standard of $\beta$-sitosterol-3-O- $\beta$-D-glucoside was available.

Fresh ginseng ( $P$. ginseng) was cultivated of ground dried roots ginseng (6 years old) in Ganghwado, South Korea. A voucher specimen (No. PG-R-11) has been deposited at the Department of Applied Life Science, Konkuk University. Red ginseng was prepared by using non-peeled fresh ginseng, which was steamed at $98-100{ }^{\circ} \mathrm{C}$ for $2 \mathrm{~h}$ using an autoclave. The steamed ginseng after drying and powdered (297.8 g) was prepared for extraction.

Extraction of Korean red ginseng powder: The Korean red ginseng powder $(297.8 \mathrm{~g})$ was extracted with $\mathrm{MeOH}(1 \mathrm{~L}$ $\times 3$ ) for three days at room temperature and then the supernatant was concentrated under vacuum to yield (30.1) $\mathrm{g}$ of the extract, which was suspended in water and extracted with hexane, ethyl acetate and n-butanol successively to produce $5 \mathrm{~g}, 8.9 \mathrm{~g}$ and $14.2 \mathrm{~g}$ extract, respectively.

Isolation of the compounds from $\boldsymbol{n}$-butanol extract: The entire butanol extract was subjected to normal phase column chromatography over silica gel $(600 \mathrm{~g})$ to yield 26 fractions (each of $500 \mathrm{~mL}$ ) with the following eluants: fractions 1-2 with chloroform, fractions 3-4 with chloroformmethanol (9.8:0.2), fractions 5-6 with chloroform-methanol (9.5:0.5), fractions 7-8 with chloroform-methanol (9:1), fractions 9-10 with chloroform-methanol (8:2), fractions 1112 with chloroform-methanol (6:4), fractions 13-14 with chloroform-methanol (4:6), fractions 15-16 with chloroformmethanol (6:4), fractions 17-18 with chloroform-methanol (3:7), fractions 19-20 with chloroform-methanol (8:2), fractions 21-22 with chloroform-methanol (1:9) and fractions 23-26 with methanol. All fractions were examined by TLC. Fractions 1-4 were not further separated due to the low amount of the substance. Fractions 5-6 (0.87 g) were obtained white powder after the purification by column chromatography, yielding $\beta$-sitosterol- $\beta$-D-glucoside $(20 \mathrm{mg})$ whose identity was confirmed through the comparison of TLC and spectroscopic data with those of an authentic sample. Fractions 7-8 (1.4 g) was re-chromatographed over LiChroprep RP-18 (ODS silica gel; 40-63 $\mu \mathrm{m}$ : $200 \mathrm{~g}$; each fraction $100 \mathrm{~mL}$ ). The elution was sequentially performed with methanol and water to yield 20 fractions. Fractions 1-4 with water-methanol (8:2), fractions 5-8 with water -methanol (6:4), fractions 9-12 with watermethanol (4:6), fractions 13-16 with water-methanol (2:8), 1720 with methanol. Fractions 9-12 after rechromatography over Lichroprep RP18 ODS (80 g, each fraction of $50 \mathrm{~mL}$ ). The elution was sequentially performed with methanol containing $80,60,40,20,10$ and $0 \%$ of water to yield one new compound $1(50 \mathrm{mg})$ in $20 \%$ fraction.

Dammar-9(11), 24-dien-3 $\beta$-ol-3 $\alpha$-L-arabinosyl-7 $\alpha$ octanoate (1): White powder; $[\alpha]_{\mathrm{D}}{ }^{21}+47.8(\mathrm{c} 0.23, \mathrm{MeOH})$; IR spectrum $\left(\mathrm{KBr}, \mathrm{v}_{\max }, \mathrm{cm}^{-1}\right): 3358,3266,2931,2852,1721$, $1453,1372,1071,1023,895,752 ;{ }^{1} \mathrm{H}(600 \mathrm{MHz})$ and ${ }^{13} \mathrm{C}$ NMR (150 MHz, $\mathrm{CD}_{3} \mathrm{SOCD}_{3}, \delta$ ) (Table-1); FAB MS (positive mode) $m / z 703[\mathrm{M}+\mathrm{H}]^{+}\left(\mathrm{C}_{43} \mathrm{H}_{75} \mathrm{O}_{7}\right)(2.1)$.

Acid hydrolysis of compound 1: Compound 1 (10 mg) was refluxed with $4 \mathrm{~mL}$ of $1 \mathrm{~mol} / \mathrm{L}$ hydrochloric acid:dioxane $(1: 1, \mathrm{v}: \mathrm{v})$ in water bath for $4 \mathrm{~h}$. The reaction mixture was work up and partitioned with chloroform and water four times and concentrated. The chloroform extract contained the aglycone portion while the water extract contained arabinose part (Cochromatographed on TLC with authentic sample).

\begin{tabular}{|c|c|c|}
\hline \multicolumn{3}{|c|}{$\begin{array}{c}\text { TABLE- } 1 \\
{ }^{1} \mathrm{H}(600 \mathrm{MHz}) \text { AND }{ }^{13} \mathrm{C} \text { NMR }(150 \mathrm{MHz}) \text { NMR DATA FOR } \\
\text { COMPOUND } 1 \text { IN } \mathrm{CD}_{3} \mathrm{SOCD}_{3}(\mathrm{~J} / \mathrm{Hz} \text { IN PARENTHESIS })\end{array}$} \\
\hline Position & ${ }^{1} \mathrm{H}$ NMNR & ${ }^{13} \mathrm{C}$ NMR \\
\hline 1 & $1.71 \mathrm{~m}, 1.68 \mathrm{~m}$ & 34.11 \\
\hline 2 & $2.02 \mathrm{~m}, 1.96 \mathrm{~m}$ & 29.33 \\
\hline 3 & $3.73 \mathrm{dd}(5.6,8.8)$ & 75.11 \\
\hline 4 & - & 40.07 \\
\hline 5 & $0.73 \mathrm{~d}(10.8)$ & 56.28 \\
\hline 6 & $1.62 \mathrm{~m}, 1.29 \mathrm{~m}$ & 17.76 \\
\hline 7 & $4.23 \mathrm{dd}(4.2,5.4)$ & 65.03 \\
\hline 8 & - & 39.72 \\
\hline 9 & - & 128.07 \\
\hline 10 & - & 36.91 \\
\hline 11 & $5.33 \mathrm{t}(7.2)$ & 122.20 \\
\hline 12 & $2.34 \mathrm{~d}(7.2)$ & 25.64 \\
\hline 13 & $1.69 \mathrm{~m}$ & 50.78 \\
\hline 14 & - & 50.09 \\
\hline 15 & $1.50 \mathrm{~m}, 1.43 \mathrm{~m}$ & 31.91 \\
\hline 16 & $1.31 \mathrm{~m}, 1.23 \mathrm{~m}$ & 29.22 \\
\hline 17 & $1.96 \mathrm{~m}$ & 50.01 \\
\hline 18 & 0.88 br s & 15.69 \\
\hline 19 & 1.02 br s & 16.75 \\
\hline 20 & $1.23 \mathrm{~m}$ & 34.11 \\
\hline 21 & $0.97 \mathrm{~d}(7.2)$ & 24.86 \\
\hline 22 & $1.36 \mathrm{~m}, 1.84 \mathrm{~m}$ & 31.51 \\
\hline 23 & $2.03 \mathrm{~m}, 2.09 \mathrm{~m}$ & 27.94 \\
\hline 24 & $5.37 \mathrm{t}(6.0)$ & 124.12 \\
\hline 25 & - & 130.24 \\
\hline 26 & 1.63 br s & 27.19 \\
\hline 27 & $1.70 \mathrm{br} \mathrm{s}$ & 21.07 \\
\hline 28 & $1.31 \mathrm{br} \mathrm{s}$ & 22.68 \\
\hline 29 & 0.89 br s & 29.35 \\
\hline 30 & 0.87 br s & 16.34 \\
\hline $1^{\prime}$ & $4.69 \mathrm{~d}(6.1)$ & 104.83 \\
\hline $2^{\prime}$ & $3.59 \mathrm{~m}$ & 74.03 \\
\hline $3^{\prime}$ & $3.40 \mathrm{~m}$ & 73.24 \\
\hline $4^{\prime}$ & $4.12 \mathrm{~m}$ & 65.31 \\
\hline $5^{\prime}$ & 3.82 br s & 61.70 \\
\hline $1 "$ & - & 171.64 \\
\hline $2^{\prime \prime}$ & $2.77 \mathrm{t}(7.2)$ & 39.33 \\
\hline $3 "$ & $1.52 \mathrm{~m}$ & 30.92 \\
\hline $4 "$ & 1.26 br s & 30.15 \\
\hline $5^{\prime \prime}$ & $1.26 \mathrm{br} \mathrm{s}$ & 29.69 \\
\hline $6 "$ & $1.26 \mathrm{br} \mathrm{s}$ & 29.69 \\
\hline $7 "$ & $1.26 \mathrm{br} \mathrm{s}$ & 22.57 \\
\hline $8 "$ & $0.82 \mathrm{t}(6.7)$ & 14.10 \\
\hline
\end{tabular}

\section{RESULTS AND DISCUSSION}

Compound 1, dammar-9(11),24-dien-3 $\beta$-ol-3 $\alpha$-Larabinosyl- $7 \alpha$-octanoate was obtained as a colourless amorphous powder from chloroform: methanol (9:1). The IR spectrum showed characteristic absorption bands for hydroxyl groups $\left(3350,3266 \mathrm{~cm}^{-1}\right)$, ester function $\left(1721 \mathrm{~cm}^{-1}\right)$ and aliphatic chain $\left(752 \mathrm{~cm}^{-1}\right)$. Its molecular ion peak was determined at $m / z, 703[\mathrm{M}+\mathrm{H}]^{+}$by combination of FAB mass and ${ }^{13} \mathrm{C}$ NMR spectra corresponding to the molecular formula of triterpenic glycosidic ester, $\mathrm{C}_{43} \mathrm{H}_{75} \mathrm{O}_{7}$. 
The ${ }^{1} \mathrm{H}$ NMR of 1 showed two one-proton triplet at $\delta 5.37$ $(J=6.0)$ and $5.33(J=7.2 \mathrm{~Hz})$, assigned to vinylic $\mathrm{H}-24$ and $\mathrm{H}-11$, respectively. Two one-proton double doublets at $\delta 3.73$ $(J=5.6,8.8 \mathrm{~Hz})$ and $4.23(J=4.2,5.4 \mathrm{~Hz})$ and one-proton doublet at $\delta 4.69(J=6.1 \mathrm{~Hz})$ were ascribed to oxygenated methine $\mathrm{H}-3 \alpha, \mathrm{H}-7 \beta$ and anomeric $\mathrm{H}-1$ ' protons, respectively. The other sugar protons resonated from $\delta 4.12$ to 3.82. A twoproton triplet at $\delta 2.77(\mathrm{~J}=7.2 \mathrm{~Hz})$ and two signals as a doublet at $\delta 0.97(3 \mathrm{H}, J=7.2 \mathrm{~Hz})$ and as a triplet at $\delta 0.82(3 \mathrm{H}, J=6.7$ $\mathrm{Hz}$ ) were attributed correspondingly to methylene H2-2" nearby to the ester function and to secondary C-21 methyl and primary C-8" methyl protons. Five three-proton singlets at $\delta 0.88,1.02,1.31,0.89,0.87,1.63$ and 1.70 were associated with the tertiary C-18, C-19, C-28, C-29 and C-30 methyl protons attached to the vinylic $\mathrm{C}-25$ carbon.

The ${ }^{13} \mathrm{C}$ NMR spectrum of $\mathbf{1}$ showed signals for vinylic carbons at $\delta 128.07$ (C-9), 122.20 (C-11), 124.12 (C-24) and $130.24(\mathrm{C}-25)$, ester carbon $171.64(\mathrm{C}-1 ")$, oxygenated methine carbons at $\delta 75.11(\mathrm{C}-3)$ and $65.03(\mathrm{C}-7)$, anomeric carbons at $104.83\left(\mathrm{C}-1^{\prime}\right)$, other sugar carbons between $\delta 74.03-61.70$ and methyl carbons from $\delta 29.35$ to 14.10 . The ${ }^{1} \mathrm{H}-{ }^{1} \mathrm{H}$ COSY spectrum of 1 showed correlations of $\mathrm{H}-3$ with $\mathrm{H}_{2}-2$, Me-28 and $\mathrm{H}_{-}$; $\mathrm{H}-7$ with $\mathrm{H}_{2}-6$, Me-18 and $\mathrm{H}_{2}-2$ "; $\mathrm{H}-11$ with Me-19, $\mathrm{H}_{2}-12$ and $\mathrm{H}-13$ and $\mathrm{H}-24$ with $\mathrm{H}_{2}-23, \mathrm{Me}-26$ and Me-27. The HMBC spectrum of 1 exhibited interactions of C-1' with $\mathrm{H}-2$ ' and $\mathrm{H}-3$; C-1" with $\mathrm{H}-7$ and $\mathrm{H}_{2}-2$ "; C-9 with Me-19, H-12 and $\mathrm{H}-13$; and C-25 with $\mathrm{H}_{2}-23, \mathrm{H}-24, \mathrm{Me}-26$ and Me-27. The interactions of $\mathrm{C}-1^{\prime}$ at $\delta 4.69$ with $\mathrm{H}-1$ ' at $\delta 104.83$; $\mathrm{C}-3$ at 75.11 with $\mathrm{H}-3$ at $\delta 3.78$; $\mathrm{C}-7$ at $\delta 65.03$ with $\mathrm{H}-7$ at $\delta$ 4.23; $\mathrm{C}-11$ at $\delta 122.20$ with $\mathrm{H}-11$ at $\delta 5.33$; and $\mathrm{C}-24$ at $\delta 124.12$ with $\mathrm{H}-24$ at $\delta 5.37$ were established by HSQC spectrum. The ${ }^{1} \mathrm{H}$ and ${ }^{13} \mathrm{C}$ NMR spectral data of $\mathbf{1}$ with compared with the reported data of dammarene triterpenoids ${ }^{13-15}$. Acid hydrolysis of $\mathbf{1}$ yielded arabinose as sugar moiety and caprylic acid (TLC comparable). On the basis of the foregoing account the structure of 1 was formulated as dammar-9(11),24-dien-3 $\beta$ ol-3 $\alpha$-L-arabinosyl-7 $\alpha$-octanoate (Fig. 1). This is new dammarene arabinoside.

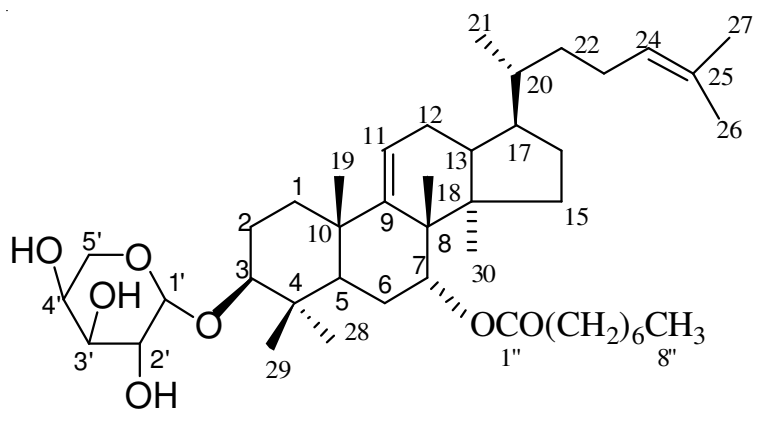

Fig. 1. Structure of compound

\section{ACKNOWLEDGEMENTS}

This work was carried out with the support of Cooperative Research Program for Agriculture Science \& Technology Development (PJ0083022011), Rural Development Administration, Republic of Korea.

\section{REFERENCES}

1. H.M. Chang and P.P. But, Pharmacology and Application of Chinese Materia Medica, vol. 1, p. 17 (1986).

2. D.S. Han, Pharmacognosy, Dong Myoung Sa, Seoul (1988).

3. W.Y. Kim, J.M. Kim, S.B. Han, S.K. Lee, N.D. Kim, M.K. Park, C.K. Kim and J.H. Park, J. Nat. Prods., 63, 1702 (2000).

4. T. Takaku, K. Kameda, Y. Matsuura, K. Sekiya and H. Okuda, Planta Medica, 56, 27 (1990).

5. S.D. Lee and H. Okuda, Korean J. Ginseng Sci., 14, 67 (1990).

6. J.H. Do, H.O. Lee, S.K. Lee, K.B. Noh, S.D. Lee and K.S. Lee, Korean J. Ginseng Sci., 17, 145 (1993).

7. S. Sanada, N. Kondo, J.O. Shoji, O. Tanaka and S. Shibata, Chem. Pharm. Bull., 22, 421 (1997).

8. K.Y. Nam, Contemporary Korean Ginseng: Chemical Constituents and Biological Activity, Korea ginseng and Tobacco Research Institute: Daejeon, Korea, Chapter 3, pp. 56-134 (1986).

9. T.K. Yun, Y.S. Lee, Y.H. Lee, S.I. Kim and H.Y. Yun, J. Korean Med. Sci., 16 (Suppl.), S6 (2001).

10. A.S. Attele, Y.P. Zhou, J.T. Xie, J.A. Wu, L. Zhang, L. Dey, W. Paugh, P.A. Rue, K.S. Polonsky and C.S. Yuan, Diabetes, 51, 1851 (2000).

11. K. Hirakura, M. Morita, K. Nakajima, Y. Ikeya and H. Mitsuhashi, Phytochemistry, 31, 899 (1992).

12. S.C. Shim, S.K. Chang, C.W. Hur and C.A. Kim, Phytochemistry, 26, 2849 (1987).

13. I.H. Park, N.Y. Kim, S.B. Han, J.M. Kim, S.W. Kwon, H.J. Kim, M.K. Park and J.H. Park, Arch. Pharm. Res., 25, 428 (2002).

14. J.H. Ryu, J.H. Park, J.H. Eun, J.H. Jung and D.H. Sohn, Phytochemistry, 44, 931 (1997).

15. N.I. Baek, D.S. Kim, Y.H. Lee, J.D. Park, C.B. Lee and S.I. Kim, Planta Medica, 62, 86 (1996).

16. S.I. Kim, J.D. Park, Y.H. Lee, G.Y. Nam and N.I. Baek, Korean J. Ginseng Sci., 15, 188 (1991).

17. C.Z. wang, H.H. Aung, B. Zhang, S. Sun, X.L. Li, H. He, J.T. Xie, T.C. He, W. Du and C.S. Yuan, Anticancer Res., 28, 2545 (2008).

18. C.Z. Wang, X. Luo, B. Zhang, W.X. Song, M. Ni, S. Mehendale, J.T. Xie, H.H. Aung, T.C. He and C.S. Yuan, Cancer Chemother. Pharmacol., 60, 69 (2007a).

19. C.Z. Wang, M. Ni, S. Sun, X.L. Li, H. He, S. Mehendale and C.S. Yuan, J. Agric. Food Res., 57, 2363 (2009).

20. C.Z. Wang and C.S. Yuan, Am. J. Chin. Med., 36, 1019 (2008b).

21. C.Z. Wang, H.H. Aung, M. Ni, J.A. Wu, R. Tong, S. Wick, T.C. He and C.S. Yuan, Planta Med., 73, 669 (2007b).

22. L.W. Qi, C.Z. Wang and C.S. Yuan, Nat. Prod. Rep., 28, 467 (2011).

23. I.M. Chung, P. Nagella and A. Ahmad, Asian J. Chem., 25, 1086 (2013). 